\title{
The Truthmaker Non-Maximalist's Dilemma
}

\author{
Mark Jago Forthcoming in Mind. Draft of November 201 I.
}

Abstract: Amongst those who feel the pull of the truthmaker principle (that truths require for their truth a truthmaker to exist), there is disagreement as to whether it applies to all truths or merely to some distinguished subset. Those in the latter camp, the non-maximalists, argue that 〈there are no ducks in my bath〉 is true not because of something's existence, but because of the lack of ducks in my bath. Maximalists, by contrast, insist that truths are made true by something's existence, and so appear to be committed to strange 'negative' entities in their ontology. As a consequence, non-maximalists appear to have a more common-sense ontology than maximalists. But things are not so straightforward. I will argue that if maximalism is committed to strange entities then so is non-maximalism; and if non-maximalism can do without strange entities, then so can maximalism. Either way, the non-maximalist has no ontological advantage over the maximalist.

\section{Introduction}

As anyone who takes an interest in Australian poetry knows, Ern Malley does not exist. He never did exist: he was invented as a hoax. At the time, however, many believed he did exist. What made their belief false, and our belief that Ern does not exist true? That is a question which has puzzled philosophers far more than Ern Malley puzzled Australian critics. For truth is something which depends on the world, and yet we have true beliefs about Ern, apparently without anything in the world to make those beliefs true.

Philosophers diverge on what to say about truth in cases such as these. Some claim that there is no good reason to think that truths need to be made true (Liggins 2008), or that truths are made true but not by entities (Melia 2005). At the other extreme, truthmaker maximalists such as Armstrong (2004), Cameron (2007), and Schaffer (2010) think that every truth is made true by some entity or other. Of interest to this paper is the intermediate position, held by Simons (2005) and Mellor (2003; 2009), on which some truths are made true but some, including truths about Ern's non-existence, are not made true by anything. Of such truths Lewis says,

It seems, offhand, that they are true not because things of some kind do exist, but rather because counter-examples do not exist. They are true for lack of false-makers. Why defy this first impression? (Lewis I992, pp. 218-I9)

Why, indeed? It certainly seems that this middle-ground position, which I shall call non-maximalism about truthmakers, stakes the best claim to common sense. ${ }^{\mathrm{I}}$ As is often the case with intermediate philosophical positions, however, the nonmaximalist's lot is not all plain sailing. This paper concerns the debate between

I. As I shall use the term, 'non-maximalism' is a theory of how the presence or absence of truthmakers for certain propositions determines the truth or falsity of those and other propositions. It is not merely the denial of maximalism. 
maximalists and non-maximalists. I shall argue that the non-maximalist's position is untenable. Her theory of truthmaking commits her to those parts of the maximalist theory which she rejects.

The debate between the maximalist and the non-maximalist has significance for at least three larger questions: the nature or essence of truth, the effectiveness of truthmaker arguments against various ontologies, and the viability of truthmaker theory itself. The first concerns the claim that what it is for a proposition $\langle A\rangle$ to be true is for it to be made true, so that truthmaking is constitutive of truth. This is one way to make sense of truth as a substantial property (or relation, in this case), as opposed to a minimal property (Wright I992) or a purely logical property (Horwich I990). But it is an option only so long as the truths and the truthmade coincide; that is, just so long as maximalism holds. For if there any truths which are not made true, then truthmaking cannot be the essence of truth.

Second, consider the various attempts that have been made to use truthmaker theory to 'catch cheats' (Sider 2003; Armstrong 2004): to argue against presentism for example, on the basis that it posit truths (about the past and future) but denies any corresponding ontology. Such moves have most force given maximalist assumptions. ${ }^{2}$ Finally, if what I argue here is correct, then truthmaking theory itself requires maximalism. But maximalism comes with a cost, either to one's ontology or to one's account of necessity (Sect. 2). So truthmaker theory itself bears that cost. If one rejects maximalism because that cost is perceived to be too high, one thereby rejects truthmaker theory itself. But by the same token, reasons for thinking that the basic truthmaker intuition is correct become reasons for accepting the cost which maximalism brings with it.

I shall limit the discussion to the debate between truthmaker maximalists and non-maximalists, and put off the question of whether truths need truthmakers at all. In section 2, I set out the cost of maximalism, which the non-maximalist hopes to avoid with her account of truthmaking. This account is set out in section 3. In section 4 and section 5, I argue that the non-maximalist is unsuccessful in this aim: she too incurs the costs set out in section 2. Finally, in section 6, I briefly discuss where this leaves truthmaker theory.

\section{The Challenge to the Maximalist}

In this section, I set out the non-maximalist's challenge to the maximalist. The challenge is in two parts: first—as a first pass-that the maximalist is committed to dubious entities in order to provide truthmakers for the 'negative' truths (such as (I) below); and second, that such entities are unnecessary, for the non-maximalist's theory shows how to account for all truths in terms of the existence or nonexistence of truthmakers, without assuming that all truths themselves have a truthmaker.

To assess the challenge, we need to understand what these 'dubious' entities

2. If we grant that 'negative' truths about what does not exist require no truthmakers, then we cannot insist that a presentist provide truthmakers for truths about the past or future (Tallant 2009). 
are, why they're supposed to be dubious and why the maximalist is supposed to be committed to them. The basic worry for the maximalist is this. A truthmaker $x$ for a proposition $\langle A\rangle$ is supposed to be an entity such that $\langle A\rangle$ is true in virtue of $x$ 's existence. Yet propositions such as

(I) $\langle$ Ern does not exist $\rangle$

(2) 〈there are no ducks in my bathtub〉

state absences of particular things. They do not appear to be true because anything particular exists-rather, they appear to be true because certain things do not exist.

A sharper form of the problem is this. Most truthmaker theorists accept truthmaker necessitarianism: that an entity $x$ is a truthmaker for a proposition $\langle A\rangle$ only if, necessarily, $\langle A\rangle$ is true if $x$ exists. ${ }^{3}$ Thus, a truthmaker $x$ for (I) must be such that, necessarily, $x$ exists only if Ern does not, and a truthmaker $y$ for (2) must be such that, necessarily, $y$ exists only if there are no ducks in my bath. The problem is, how could there be any such entity? For the purposes of the dispute between the maximalist and the non-maximalist, we will assume truthmaker necessitarianism. Without it, the tension between the maximalist and the non-maximalist vanishes. The non-maximalist does not deny that there are entities (perhaps, the whole world and my bath, respectively) which are relevant to whether (I) and (2) are true. What she denies is that these entities make those truths true. Why? Presumably, because those entities could have existed without those truths being true. In other words, the non-maximalist assumes truthmaker necessitarianism in making her case agains the maximalist. Since most maximalists also accept necessitarianism (that's why they have to go to lengths to develop a maximalist account), it is appropriate to accept it here.

According to Molnar (2000, pp. 84-5), entities which necessitate the nonexistence of some entity are 'mysterious' (2000, p. 76) and 'radically acausal' (2000, p. 77), which Molnar takes as reasons for thinking that such 'negative' entities-including absences qua genuine entities (Martin I996; Kukso 2006), negative facts (Jago and Barker 20II), and totality facts (Armstrong I997; 2004)do not exist. The notion of a 'negative' entity is a rather obscure one, as both Parsons (2006) and Cameron (2007) point out. ${ }^{4} \mathrm{I}$ do not think we can give a good general definition of the 'negative' entities to which the maximalist is supposed to be committed. We cannot align them with those entities which (according to the maximalist) make some negative existential true: $\langle\neg \exists x x$ makes $\langle$ Max does not exist $\rangle$ true $\rangle$ is a true negative existential, and it's highly plausible that Max's existence makes it true. But we clearly do not want to count Max as a negative entity. Nor are the negative entities those entities which (according to the maximalist) make nothing but negative existentials true, for there are no such

3. Parsons (1999) and Mellor (2009) are exceptions. Note that Mellor rejects necessitation only for the case of general truths. I will make use only of instances of necessitation which he accepts.

4. Parsons (2006) argues that, whilst we can understand 'negative proposition' in terms of certain representational properties, this will not help us to understand what it is for non-representational entities (such as facts) to be 'negative'. 
entities. ${ }^{5}$ Nor are negative entities are those which, due to their intrinsic properties, exclude other contingent entities from existing, for Max excludes his absence, just as his absence excludes Max. Yet Max is a positive entity if any is. For the purposes of this discussion, we can bypass attempts to give a general characterisation of 'negative' entities and instead put the non-maximalist's challenge in more specific terms. She wants to avoid commitment to negative facts, absences (qua entities) and totality facts.

There have been attempts to develop a maximalist account without relying on such entities. Lewis, based on his Humean rejection of necessary connections and exclusions between distinct entities (Lewis I986), rejects all such entities. But he nevertheless finds himself able to offer an account of truthmaking (Lewis 2003). This lemon, when picked out qua juicy, is (according to Lewis's theory) necessarily juicy. For when the lemon's juiciness is raised to salience, the counterpart relation relates that lemon only to other juicy things. In that context, the lemon itself is a suitable entity for guaranteeing the truth of $\langle$ this lemon is juicy $\rangle$. In their postscript to Lewis's paper, Lewis and Rosen (2003) extend the idea to cover negative existentials. They take (2) to be made true by my bath, qua unaccompanied by ducks, and (I) to be made true by the world, qua unaccompanied by Ern. On this story, one gets maximalism on the cheap. One does not need to introduce extra entities to deal with truths like (I) and (2). Cameron (2007) gives a similar account to Lewis and Rosen's, except that he rejects the multiplicity of counterpart relations which Lewis and Rosen require. Unlike Lewis and Rosen, he holds that the world is essentially the way it is, and that it makes all the negative truths true.

Although they do not posit new and strange entities to account for the negative truths, these accounts have other costs. Lewis's account seems to cheapen the idea of truthmaking to the point of triviality: we surely do not want to count my left ear, qua inhabitant of an Ernless world, as a truthmaker for (I). Cameron gives up on the context-sensitivity of the counterpart relation (one of the main strengths of Lewis's theory) and requires the strong assumption that the world could not have been any way other than the way it is.

These are the maximalist's options in dealing with negative truth: either accept extra entities into the ontology which do the required truthmaking work intrinsically, or adopt a theory of necessity on which ordinary entities necessitate the negative truths. I'll call these strategies ontology maximalism and necessity maximalism respectively. The non-maximalist rejects both. She rejects ontology maximalism on the basis that the entities it postulates are absurd. She rejects necessity maximalism because she rejects meddling with counterpart relations in this way. Moreover, she finds both options unnecessary, for she can provide a theory of truthmaking which does not require a truthmaker for every truth. It is to the details of this theory that we now turn.

5. Suppose (for reductio) that $x$ is one of those entities. Then $\langle x$ exists $\rangle$ is true, and $x$ is its truthmaker. So $x$ makes something other than a negative existential true: contradiction. 


\section{The Non-Maximalist Account}

In the previous section, I reviewed the non-maximalist's reasons for rejecting maximalism. In this section, I discuss how the non-maximalist should develop a theory of truthmaking which does not require a truthmaker for every truth. By non-maximalist theory, I mean a theory which accounts for the truth or falsity of each proposition in terms of the existence or non-existence of truthmakers, either for that proposition or for other propositions, without requiring each true proposition to have a truthmaker.

In developing such a theory, the non-maximalist's guiding insight is that propositions such as (I) are true not because of what does exist, but because of what does not-specifically, because Ern does not exist. And propositions such as (2) are true because of how things are not: (2) is true because of the lack of ducks in my bath. This contrasts with the negations of (I) and (2) which, if they were true, would be true because of Ern's existence and the existence of ducks in my bath.

Guided by this intuition, the non-maximalist isolates a class of propositions which, if true, are made true by the existence of some entity or other. I will call these the positive propositions. ${ }^{6}$ Typically, it is the negations of these propositions (and the negations of the existentially quantified ones in particular) which are the focus of the debate between the maximalist and the non-maximalist. The non-maximalist takes propositions such as (I) and (2) to require no truthmaker in order to be true. ${ }^{7}$ As Lewis (1992, pp. 21 8-19) says, they are true in virtue of the absence of a falsemaker. I will call such propositions the negative propositions.

Kukso (2006) outlines the non-maximalist approach to negative truths, according to which 'a negative truth is true just in case the truthmaker for the corresponding positive proposition is absent, and it is false just in case it is present' (2006, p. 28). The 'corresponding positive proposition' to a negative proposition $\langle\neg A\rangle$ is $\langle A\rangle$ and, for a negative proposition $\langle B\rangle$ not of the form $\langle\neg A\rangle$, the corresponding positive proposition is its negation, $\langle\neg A\rangle .^{8}$ As positive truths may have more than one truthmaker, a non-maximalist should say that a negative proposition is true iff the corresponding positive proposition lacks any truthmaker.

The account I will call simple non-maximalism takes each proposition to be either positive or negative, with the truth of negative propositions determined in the way just described. Kukso (2006) and Mumford (2007), for example, assume that all truths are either positive or negative. It is not difficult to see that the simple non-maximalist account is in trouble. For consider the proposition

(3) 〈there are ducks in my bathtub $\vee$ there are no lemons in my fridge〉

6. Mellor (2009) calls them the 'primary' propositions.

7. One might hold that, since 'Ern Malley' is an empty name, (I) is not truth apt. I'll require a truth which by non-maximalist lights has no truthmaker. So if you hold that (I) is not truth apt, you should substitute (2) for (I) throughout, including where (I) is embedded within knowledge claims.

8. One might add that whatever makes $\langle A\rangle$ true also makes $\langle\neg \neg A\rangle$ true and vice versa, but I will not rely on this assumption. 
and assume it is false. By the non-maximalist's lights, 〈there are no lemons in my fridge $\rangle$ is a negative proposition, which needs no truthmaker to be true. If there were no ducks in my bath and no lemons in my fridge, 〈there are no lemons in my fridge $>$ and hence (3) would be true, but they would not have truthmakers, according to the non-maximalist. So the simple non-maximalist must take (3), as a proposition which does not require a truthmaker for its truth, to be negative and hence false iff its negation

(4) $\langle\neg$ (there are ducks in my bathtub $\vee$ there are no lemons in my fridge) $\rangle$

has a truthmaker. But, by the non-maximalist's own lights, (4) actually has no truthmaker. (4) is true because there are lemons in my fridge but no ducks in my bathtub. The lemons in the fridge alone do not make (4) true, as it is possible for there to be lemons in my fridge and yet for $(4)$ to be false. If (2) has no truthmaker, as the non-maximalist claims, then (4) has no truthmaker either. But then, on the simple non-maximalist story, (3) comes out true, contrary to our assumption, for (3) is taken to be true iff $(4)$ has no truthmaker. Hence the simple non-maximalist strategy of exhaustively classing every proposition as either positive or negative, and analysing the truth of each negative proposition in terms of the absence of any truthmaker for the corresponding positive proposition, is doomed.

To avoid the problem, the non-maximalist should not take every proposition to be either positive or negative. She should allow a class of derivative propositions, which derive their truth or falsity from the truth or falsity of more logically basic propositions. ${ }^{9}$ On this account, a true conjunction $\langle A \& B\rangle$ derives its truth from the truth of both $\langle A\rangle$ and $\langle B\rangle$; whereas a false conjunction $\langle A \& B\rangle$ derives its falsity from the falsity of either $\langle A\rangle$ or of $\langle B\rangle$. Similarly, a true disjunction $\langle A \vee B\rangle$ derives its truth from the truth of either $\langle A\rangle$ or of $\langle B\rangle$, whereas a false disjunction $\langle A \vee B\rangle$ derives its falsity from the falsity of both $\langle A\rangle$ and $\langle B\rangle$. A true negation $\langle\neg A\rangle$ derives its truth from the falsity of $\langle A\rangle$, whereas a false negation $\langle\neg A\rangle$ derives its falsity from the truth of $\langle A\rangle .{ }^{10}$ On this account, we analyse a complex proposition $\langle A\rangle$ by recursing through these clauses until we have a condition for $\langle A\rangle$ 's truth in terms positive propositions only. This clause connects $\langle A\rangle$ 's truth or falsity to the presence or absence of truthmakers for those positive propositions.

Call this the sophisticated non-maximalist account. It takes all propositions to be either positive, negative, or derivative. ${ }^{\text {II }}$ It easily avoids the problem just posed for simple non-maximalism. On the sophisticated account, (3)'s truth is derivative either on the existence of a truthmaker for 〈there are ducks in my bathtub) or on the absence of a truthmaker for 〈there are lemons in my fridge $\rangle$. Hence the

9. Mellor $(2003 ; 2009)$ gives an account along these lines.

I0. Similar clauses can be given for existential and universal propositions. We are using the standard recursion clauses of model theory for a first-order language, except we have a dependence claim rather than a biconditional. In our case, the recursion terminates once all non-positive propositions have been analysed. The non-maximalist may, but need not, align the non-positive propositions with the logically complex ones; in which case, the recursion terminates with atomic propositions.

I I. Note that, on the definition just given, negative propositions are a special case of derivative propositions. For positive propositions $\langle A\rangle,\langle\neg A\rangle$ 's truth is derivative on $\langle A\rangle$ 's lacking a truthmaker and $\langle\neg A\rangle$ 's falsity is derivative on $\langle A\rangle$ 's having a truthmaker. Hence by definition, $\langle\neg A\rangle$ is a negative proposition. 
theory tells us, correctly, that $(3)$ is true iff either there's ducks in my bath or no lemons in my fridge. I'll assume that the non-maximalist accepts the sophisticated account, or one similar to it, and so classifies propositions into positive, negative, and derivative. She thus has a theory on which all propositions can be evaluated for truth in terms of the existence or non-existence of truthmakers. If the theory is successful, it shows that one need not assume that all propositions need a truthmaker to be true. So, with justification, she asks the maximalist: why insist that all truths have a truthmaker?

In the remainder of the paper, I'll argue that the non-maximalist is faced with a dilemma. Either she too must accept the necessity maximalist's explanation of truthmaking, or she must accept at least some of the objectionable entities from the ontology maximalist's ontology. Either way, I'll argue, her ontology collapses into a maximalist one. The non-maximalist then has no argument against the maximalist.

\section{The Maximalist Strikes Back}

In this section and the next, I argue that there are (by the non-maximalist's lights) positive truths which nevertheless necessitate negative truths. I'll use such truths to drive the non-maximalist into either necessity maximalism or ontology maximalism. In this section I'll argue that, on the non-maximalist's account, propositions such as

(5) 〈Max knows that Ern Malley does not exist)

must be treated as positive propositions. This will be problematic for the nonmaximalist, for then she will have to find a truthmaker for (5).

First, I'll argue that (5) cannot be a negative proposition. Suppose for reductio that it is negative. Then, by definition, its negation

(6) $\langle\neg($ Max knows that Ern Malley does not exist $)\rangle$

is a positive proposition, and hence true iff it has a truthmaker. But this is the wrong result. Given the non-maximalist's ontology, there are numerous ways in which (6) could be true whilst lacking a truthmaker. Here is one such case: the hoax was never run, and no one possesses the concept Ern Malley. In this case, (6) is true because no one has any beliefs whatsoever about Ern Malley. It's true for the lack of relevant knowledge-constituting beliefs. Since the non-maximalist does not accept absences, negative facts, or totality facts, there's no entity to make (6) true. Another case: Max does not exist. Then plausibly, (6) is true because Max does not exist. Again, given the non-maximalist's ontology, there's no entity to make (6) true. So (6) is not negative, hence (5) is not positive.

For the remainder of this section, I'll argue that there are strong reasons for thinking that $(5)$ and similar propositions are not derivative either, and hence that they are positive. Suppose the non-maximalist claims that every proposition of the form $\langle x$ knows that $A\rangle$ is derivative, for every negative proposition $\langle A\rangle .{ }^{\mathrm{I} 2}$

I 2. To avoid the problem to be introduced in section 5 , the non-maximalist must hold this position. 
She cannot merely stipulate this, without saying upon which propositions they are derivative. This move would be dialectically hopeless for the non-maximalist. Recall that she charges the maximalist with being unable to provide truthmakers for all truths without invoking (what she takes to be) absurd entities. For a maximalist position to be at all plausible, one must say just what kind of entity makes truths such as (I) true. By the same token, a non-maximalist who takes (5) to be derivative must say upon which propositions it is derivative.

So, if a non-maximalist claims that every proposition $\langle x$ knows that $A\rangle$ is derivative, she needs to provide a general method for finding a set of propositions upon which $\langle x$ knows that $A\rangle$ is derivative. The relation between a derivative proposition and the propositions upon which it is derivative is a necessary one. Hence any method for finding a set of propositions on which an arbitrary proposition of the form $\langle x$ knows that $A\rangle$ is derivative would effectively provide an exceptionless set of necessary and sufficient conditions for knowledge. There is, however, an excellent reason for thinking that there are in general no such conditions, namely that the extensive literature on the Gettier problem failed to find any. Every proposed analysis of knowledge has met with counterexamples. ${ }^{\mathrm{I} 3}$

The problem for the non-maximalist (which will be introduced in section 5) is not specifically a problem about knowledge. The problem arises for the nonmaximalist if there are positive truths which necessitate negative truths. There exist such truths if there is any factive operator ' $O$ ' and negative proposition $\langle A\rangle$ such that $\langle O A\rangle$ is a positive truth. As a consequence, it would not help the nonmaximalist to claim that $\langle x$ knows that $A\rangle$ is derivative on some further factive proposition $\langle O A\rangle$. So, for example, it will not help the non-maximalist to offer a Dretske-style analysis of knowledge in terms of a factive notion of information

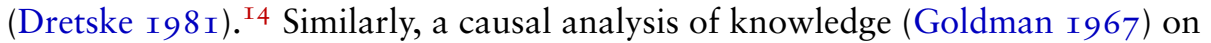
which one's knowledge that $A$ must be caused by the state of affairs that $A$ will not help, for something can be caused by the state of affairs that $A$ only if $A$. And again, according to safety accounts (Sosa I999) on which the content of a known belief is true in all closest worlds, safe beliefs are true. So analysing knowledge in terms of a causal condition, or in terms of safety, will not help the non-maximalist. We will still be left with a positive truth $\langle O A\rangle$ which entails a negative proposition $\langle A\rangle$, which is all we need to run the problem in section 5 .

In this section, I've argued that $(5)$ is neither negative nor derivative. It must therefore be positive, and so it must have a truthmaker iff it is true. In the next section, I argue that this fact poses a serious problem for the non-maximalist theory.

I3. Note that I'm not claiming that an exceptionless set of necessary and sufficient conditions is the goal of an analysis of knowledge. Rather, I'm claiming (i) that the only way to show that all propositions of the form $\langle x$ knows that $A\rangle$ are derivative is to provide an exceptionless set of necessary and sufficient conditions for knowledge; and (ii) that we have good reason for thinking that this cannot be done. I 4. As Dretske says, 'Gettier difficulties ... arise for any account of knowledge that makes knowledge a product of some justificatory relationship (having good evidence, excellent reasons, etc.) that could relate one to something false.... The [Gettier] problem is evaded in the information-theoretic model, because ... one cannot get into an appropriate informational relationship to something false' (Dretske I983, p. I79). 


\section{Tu Quoque!}

In this section, I consider the non-maximalist's options for assigning a truthmaker to (5). I'll argue that, whatever option she takes, she makes serious concessions to the maximalist.

Clearly, (5) can be true: let us suppose it is. Then, as a positive proposition, it has one or more truthmakers, according to the non-maximalist. Let $\mathbb{T}$ be one of its truthmakers. Given truthmaker necessitarianism (which the non-maximalist accepts), it is necessary that $(5)$ is true if $\mathbb{T}$ exists. As knowledge is factive, it is also necessary that $(\mathrm{I})$ is true if $(5)$ is; and it is necessary that Ern does not exist if (I) is true. So it is necessary that Ern does not exist if $\mathbb{T}$ does: $\mathbb{T}$ necessarily excludes Ern's existence. The non-maximalist, just like the maximalist, is committed to entities which necessarily exclude other entities from existence.

This is not to say that $\mathbb{T}$ is a truthmaker for (I), despite necessitating its truth. For all we have said, necessitating $\langle A\rangle$ 's truth is a necessary but insufficient condition for being one of $\langle A\rangle$ 's truthmakers. ${ }^{15}$ Nevertheless, the non-maximalist must explain (just as the maximalist must) how it can be that an entity can necessarily exclude Ern's existence. This is just the problem the maximalist faces in trying to find a truthmaker for ( $\mathrm{I}$ ): how can anything provide the necessary guarantee that Ern does not exist?

The options for the non-maximalist in explaining how $\mathbb{T}$ does what it does are just the options the maximalist has in finding truthmakers for negative truths. She must either expand her ontology, as the ontology maximalist does, to include entities such Ern's absence, or the negative fact that Ern does not exist, or a totality fact; or else she must adopt an account of necessity which allows that regular entities—baths, lemons, and so on-necessarily exclude other regular entities, as the necessity maximalist does.

We must consider two questions. First, what on such accounts is the truthmaker for $(5)$ ? and second, how does non-maximalism stand, given that it accepts such a truthmaker for (5)? Let's go through the options one by one. First, suppose the non-maximalist expands her ontology by adding suitable absences (qua genuine entities). I do not think it's plausible to take an absence itself to be the truthmaker for (5). That truth requires more than mere absence: it also requires Max to have an appropriately-formed mental state. Nevertheless, it's plausible that $(5)$ is made true by a complex involving Ern's absence itself, just as a truthmaker for $\langle$ Max knows that Alice is in the room $)$ involves Alice herself. We can thus think of Max's knowledge as knowledge of Ern's absence.

The same goes if the non-maximalist expands her ontology with appropriate negative facts. Then, the truthmaker for $(5)$ involves the negative fact that Ern Malley does not exist, and we can think of Max's knowledge as knowledge of this fact. ${ }^{\mathrm{I}}$ Ascribing Max knowledge of a totality fact, on the other hand, is at risk of

I 5 . Some truthmaker theorists accept the entailment thesis (Armstrong 2004), which says that, if $x$ is a truthmaker for $\langle A\rangle$ and $\langle A\rangle$ entails $\langle B\rangle$, then $x$ is a truthmaker for $\langle B\rangle$ too. The non-maximalist must deny the thesis, for else $\mathbb{T}$ will count as a truthmaker for (I), contrary to the non-maximalist line. Denying the entailment thesis is (independently) an attractive option (Restall I996).

I6. Indeed, one may identify the entity Ern's absence with the negative fact that Ern does not exist 
ascribing him far too much knowledge. Nevertheless, it's plausible that a totality fact is part of the truthmaker for (5). ${ }^{17}$ If instead the non-maximalist adopts the necessity maximalist's resources, the truthmaker for $(5)$ might be a complex which includes the world as a whole; or it might be Max's mental state, qua state of knowledge that Ern does not exist. Whether these accounts of what makes (5) true are satisfactory is not my concern here. The point is that the non-maximalist must adopt some account along these lines, using either the ontology maximalist's or the necessity maximalist's resources. Our question now is, how does non-maximalism stand, having adopted one of these accounts? In the remainder of the section, I'll argue that the non-maximalist account collapses into maximalism.

If the non-maximalist accepts the existence of a totality fact, she thereby accepts the totality-fact maximalist's ontology in its entirety. She no longer has any ontological advantage over the maximalist. Similarly, if she accepts Lewis and Rosen's or Cameron's account, she thereby accepts a counterpart relation (or relations) with which one can give truthmakers for all truths, and not just the positive ones. On this option, the maximalist's and the non-maximalist's ontologies coincide (this is the point of Lewis and Rosen's and Cameron's accounts), and so again, she can cite no ontological advantage over the maximalist-for in effect, she has become a maximalist.

If the non-maximalist instead opts for an explanation of (5)'s truth in terms of absences or negative facts, the case is slightly different. She thereby accepts into her ontology negative entities. She is forced into accepting the same ontological categories as the maximalist. To be sure, she is not forced into populating the 'negative' category as fully as the maximalist does. This, however, is cold comfort to the non-maximalist. She has given up her main reason for being a non-maximalist rather than a maximalist, namely revulsion at entities such as absences and negative facts. This was her main case against the maximalist's ontology.

In this section, I've argued that the non-maximalist is committed to the same ontology as a maximalist. In particular, if the non-maximalist accepts absences, negative facts, or a totality fact to account for $(5)$ 's truth, she thereby accepts a maximalist ontology. Her main case against maximalism-that it is committed to absurd entities whereas non-maximalism is not-collapses.

\section{Where Now?}

I've argued that the non-maximalist is committed to a maximalist ontology, and hence that the non-maximalist has no argument against the maximalist. Where does this leave truthmaking theory? To accept truthmaking theory, I've argued, one must either be an ontology maximalist or a necessity maximalist. I've elsewhere argued in favour of ontology maximalism, with an ontology including negative facts (Jago 20II; Jago and Barker 20II). I take absences-a kind of negative fact- to be a fundamental feature of the world. Negative facts, I claim, are causally

(Jago and Barker 20II).

I7. Perhaps Max is acquainted with that fact under certain modes of presentation (such as 'that Ern does not exist') only. 
efficacious (as in cases of causation by absence); they are perceivable (as when a batsman sees the gap at extra cover); and they feature in the constitution of material objects such as holes and edges. If I'm right, then that's good reason to accept them into our ontology, independently of the truthmaking work they do. With particular facts (including negative facts) in our ontology, moreover, we can do without totality facts and without meddling with counterpart relations to turn entities into suitable truthmakers (Jago and Barker 20II).

The arguments I've alluded to in favour of this ontology are of course controversial, and here is not the place to repeat and evaluate them. If one rejects negative facts and all the other maximalist options then, given the arguments above, one must reject truthmaking theory altogether. If one rejects truthmaker theory, it is then debatable whether one can capture the idea that truth depends on being (although see Melia 2005; Liggins 2008). ${ }^{\mathrm{I} 8}$ For my money, truthmaking theory is the best way to cash out the intuitive notion that there is an asymmetric relation of dependence from what there is to what's true. If so, given the arguments I've given here, that intuition is best captured by a theory on which being encapsulates negative facts as well as positive ones, and which provides a truthmaker for every truth.

\section{References}

Armstrong, David 1997: A World of States of Affairs. Cambridge: Cambridge University Press.

Armstrong, David 2004: Truth and Truthmakers. Cambridge: Cambridge University Press.

Beebee, Helen and Dodd, Julian (eds.) 2005: Truthmakers: the Contemporary Debate. Oxford: Oxford University Press.

Cameron, Ross 2007: 'How to be a Truthmaker Maximalist'. Nous, 42(3), 4IO-2I.

Dretske, Fred 198 I: Knowledge and the Flow of Information. Cambridge, MA: MIT Press.

Dretske, Fred I983: 'Précis of Knowledge and the Flow of Information'. Behavioral and Brain Sciences, 6(I), 55-63.

Dyke, Heather (ed.) 2009: From Truth to Reality: New Essays in Logic and Metaphysics. New York: Routledge.

Goldman, Alvin 1967: 'A Causal Theory of Knowing'. The Journal of Philosophy, 64(I2), $357-72$.

Horwich, Paul I990: Truth. Oxford: Blackwell.

Jago, Mark 20I I: 'Setting the Facts Straight'. Journal of Philosophical Logic, 40, 33-54.

I 8. Note that a supervenience thesis for truth does not capture this dependence idea. Dependence is an asymmetric relation, whereas the supervenience relation between truth and being is not: for just as there could be no difference in the truths without a difference in being, there could be no difference in being without a difference in the truths (Rodriguez-Pereyra 2005). 
Jago, Mark and Barker, Stephen 20I I: 'Being Positive About Negative Facts'. Philosophy and Phenomenological Research. Published online I7 Feb, doi: IO.IIII/j.I933I 592.2010.00479.x.

Kukso, Boris 2006: 'The Reality of Absences'. Australasian Journal of Philosophy, 84(I), $2 \mathrm{I}-37$.

Lewis, David I986: On the Plurality of Worlds. Oxford: Blackwell.

Lewis, David I992: 'Critical notice of D.M. Armstrong's A Combinatorial Theory of Possibility'. Australasian Journal of Philosophy, 70 (2), 2 I I-24.

Lewis, David 2003: 'Things qua Truthmakers'. In Lillehammer and Rodriguez-Pereyra 2003 , pp. $25-38$.

Lewis, David and Rosen, Gideon 2003: 'Postscript to 'Things qua Truthmakers': Negative Existentials’. In Lillehammer and Rodriguez-Pereyra 2003, pp. 39-42.

Liggins, David 2008: Truthmakers and the Groundedness of Truth. Proceedings of the Aristotelian Society 108, 177-96.

Lillehammer, Harvard and Rodriguez-Pereyra, Gonzalo (eds.) 2003: Real Metaphysics. London: Routledge.

Martin, C.B. I996: 'How It Is: Entities, Absences and Voids'. Australasian Journal of Philosophy, 74(I), 57-65.

Melia, Joseph 2005: 'Truthmaking without Truthmakers'. In Beebee and Dodd 2005, pp. $67-84$.

Mellor, D.H. 2003: 'Replies'. In Lillehammer and Rodriguez-Pereyra 2003, pp. 21 2-38.

Mellor, D.H. 2009: 'Truthmakers for What?'. In Dyke 2009, pp. 272-90.

Molnar, George 2000: 'Truthmakers for Negative Truths'. Australasian Journal of Philosophy, 78(I), 72-86.

Mumford, Stephen 2007: 'Negative Truth and Falsehood'. Proceedings of the Aristotelian Society, I07(I), 45-7I.

Parsons, Josh I999: 'There is no 'Truthmaker’ Argument Against Nominalism'. Australasian Journal of Philosophy, 77(3), 325-34.

Parsons, Josh 2006: 'Negative Truths From Positive Facts?' Australasian Journal of Philosophy, 84(4), 59I-602.

Restall, Greg I996: 'Truthmakers, Entailment and Necessity'. Australasian Journal of Philosophy, 74(2), 33I-40.

Rodriguez-Pereyra, Gonzalo 2005: 'Why Truthmakers'. In Dodd and Beebee 2005, pp. I7-3I.

Schaffer, Jonathan 2010: 'The Least Discerning and Most Promiscuous Truthmaker'. The Philosophical Quarterly 60(239), 307-24. 
Sider, Ted 2003: Four-Dimensionalism: an Ontology of Persistence and Time. New York: Oxford.

Simons, Peter 2005: 'Negatives, Numbers, and Necessity: Some Worries About Armstrong's Version of Truthmaking'. Australasian Journal of Philosophy, 83(2), 253-6I.

Sosa, Ernest I999: 'How to Defeat Opposition to Moore'. Philosophical Perspectives I3, I $4 \mathrm{I}-53$.

Tallant, Jonathan 2009: 'Ontological Cheats Might Just Prosper'. Analysis 69(3), 422-30. Wright, Crispin I992: Truth and Objectivity. Harvard, MA: Harvard University Press. 